\section{Commentary: The Ross procedure in a graft: A word of caution}

\author{
Elbert Williams, MD, and \\ Ismail El-Hamamsy, $\mathrm{MD}, \mathrm{PhD}$
}

The evidence is growing fast that the Ross procedure is the best operation to replace the aortic valve in young adults. ${ }^{1}$ Nevertheless, there remain 2 important concerns: durability and reproducibility. Indeed, the Ross procedure is a more involved operation and every technical detail not only influences safety, but also can influence stability of the pulmonary autograft. Wrapping the autograft in a graft aims at addressing both these issues. The graft eliminates any possibility of dilatation while also providing a more familiar to sew for many surgeons. That said, it is important to remember that the reason a Ross procedure is preferred in young adults is because it translates into near-normal long-term survival and optimal left ventricular (LV) health. This is only possible because the pulmonary autograft is a living substitute that can reproduce native aortic root structure, mimic its biology and function, and confer excellent hemodynamic parameters, both at rest and with exercise.

Starnes and colleagues ${ }^{2}$ describe a technique that led to significant improvements in autograft stability and freedom from reintervention in their experience. The authors propose to wrap the pulmonary autograft in a straight polyethylene terephthalate graft, $\sim 2$ to $4 \mathrm{~mm}$ larger than the pulmonary annulus size. In other words, if the pulmonary annulus measures $24 \mathrm{~mm}$, the selected polyethylene terephthalate tube measures $28 \mathrm{~mm}$. In their hands, this has dramatically reduced the rate of reintervention at 10 years after the Ross procedure (27\% reintervention at 10 years in the control group). In my opinion, this approach poses

\footnotetext{
From the Department of Cardiovascular Surgery, The Mount Sinai Hospital, Icahn School of Medicine at Mount Sinai, New York, NY.

Disclosures: The authors reported no conflicts of interest.

The Journal policy requires editors and reviewers to disclose conflicts of interest and to decline handling or reviewing manuscripts for which they may have a conflict of interest. The editors and reviewers of this article have no conflicts of interest.

Received for publication Sept 13, 2021; revisions received Sept 13, 2021; accepted for publication Sept 17, 2021; available ahead of print Sept 24, 2021.

Address for reprints: Ismail El-Hamamsy, MD, PhD, Department of Cardiovascular Surgery, Mount Sinai Hospital, 1190 5th Ave, New York, NY (E-mail: ismail. el-hamamsy@mountsinai.org).

JTCVS Techniques 2021;10:377-8

2666-2507

Copyright (C) 2021 The Author(s). Published by Elsevier Inc. on behalf of The American Association for Thoracic Surgery. This is an open access article under the CC BY-NC-ND license (http://creativecommons.org/licenses/by-nc-nd/4.0/).

https://doi.org/10.1016/j.xjtc.2021.09.037
}

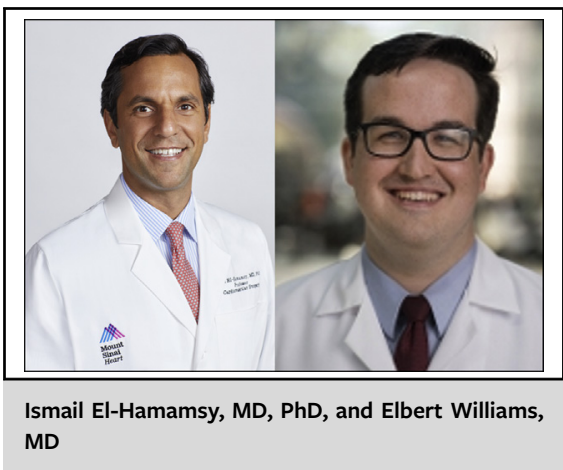

\section{CENTRAL MESSAGE \\ Wrapping the pulmonary auto- graft in a graft is an effective means to avoid dilatation. How- ever, blunting root dynamism may have unintended conse- quences. A more selective approach is warranted.}

some theoretical and practical concerns. First, placing the pulmonary autograft in a polyethylene terephthalate tube completely blunts the shape and any possibility of expansion of the sinuses of Valsalva during the cardiac cycle. Aortic root dynamism is vital to the function of the pulmonary autograft. ${ }^{3}$ Although this may sound like an academic concern, eliminating sinuses results in higher leaflet stresses, more abrupt opening and closing velocities, increased LV impedance, and absence of Eddy currents in the sinuses. This may negatively influence cusp longevity and LV health in the long term. It also translates into higher resting gradients than a standard root replacement. No hemodynamic data were provided in this technical article, but it will be interesting to evaluate the hemodynamic parameters at rest and exercise. Second, squeezing the autograft in a polyethylene terephthalate tube can result in distortion at the annulus or sinotubular junction, as well as cause relative prolapse of the cusps if the commissures are not placed at the adequate height. Unlike with valvesparing surgery, the autograft is very fragile and it is not quite so easy to determine the perfect height for implantation in a polyethylene terephthalate graft. This can result in early failures or eccentric jets of aortic regurgitation, a predictor of failure. Indeed, of the 58 patients undergoing a wrapped Ross in this series, 3 needed reintervention within the first year. These are likely related to the choice 
of surgical technique. Although results appear stable thereafter, it should be noted that thus far, $<50 \%$ of patients have 5 -year follow-up; that is, fewer than 30 patients in total.

Ultimately, we have 3 main comments. First, we believe autograft dilatation can be prevented through a combination of careful technical details (muscle trimming, implantation in the LV outflow tract, selective aortic annuloplasty, sinotubular junction stabilization, and autologous aortic jacket) and tight blood pressure control during the first 6 months. ${ }^{4}$ This preserves root viability and dynamism while mitigating root dilatation. It is a more physiological approach and preserves the Ross principle of a living aortic substitute. It can be applied to patients with stenosis or those with regurgitation and a dilated aortic annulus with equal effectiveness. ${ }^{5}$ Second, the Ross procedure is a complex operation and should be concentrated in high-volume centers. This raises the question: should (and can) we establish Ross reference centers, defined according to transparently reported volume and outcome data? Last, while we would not advocate for this technique in all patients, it is an important addition to the Ross armamentarium. It may benefit a subset of patients, namely those at highest risk of autograft dilatation or those traditionally considered noncandidates, such as patients with connective tissue disorders.

It is important to remember that the raison d'être of the Ross procedure is biology. All efforts at improving long-term durability of the operation should aim at preserving it.

\section{References}

1. Ouzounian M, Mazine A, David TE. The Ross procedure is the best operation to treat aortic stenosis in young and middle-aged adults. J Thorac Cardiovasc Surg. 2017; 154:778-82.

2. Starnes VA, Bowdish ME, Cohen RG, Baker CJ, Elsayed RS. The Ross procedure utilizing the pulmonary autograft inclusion technique in adults. J Thorac Cardiovasc Surg Tech. 2021;10:372-6.

3. Torii R, El-Hamamsy I, Donya M, Babu-Narayan SV, Ibrahim M, Kilner PJ, et al. Integrated morphologic and functional assessment of the aortic root after different tissue valve root replacement procedures. J Thorac Cardiovasc Surg. 2012;143: 1422-8.

4. Williams EE, El-Hamamsy I. The Ross procedure. Op Tech Thorac Cardiovasc Surg. 2021;26:189-209.

5. Bouhout I, Ghoneim A, Tousch M, Stevens LM, Semplonius T, Tarabzoni M, et al. Impact of a tailored surgical approach on autograft root dimensions in patients undergoing the Ross procedure for aortic regurgitation. Eur J Cardiothorac Surg. 2019;56:959-67. 